\title{
Produção e composição do leite de vacas mantidas em pastagens de capim-elefante submetidas a duas frequências de pastejo
}

\author{
Tadeu Vinhas Voltolini ${ }^{1}$, Flávio Augusto Portela Santos ${ }^{2}$, Junio Cesar Martinez ${ }^{3}$, \\ Hugo Imaizumi ${ }^{4}$, Rafael Luis Clarindo ${ }^{2}$, Marco Antonio Penati ${ }^{2}$
}

\author{
${ }^{1}$ Embrapa Semiárido, Petrolina, PE. \\ 2 Departamento de Zootecnia da Escola Superior de Agricultura "Luiz de Queiroz", Universidade de São Paulo, Piracicaba, SP. \\ 3 Pós-graduação em Zootecnia, Faculdade de Ciências Agrárias e Veterinárias - Universidade Paulista Júlio de Mesquita Filho, Jaboticabal,SP. \\ ${ }^{4}$ Dukamp Saúde Animal Ltda, Monte Aprazível,SP.
}

RESUMO - Objetivou-se avaliar duas frequências de pastejo em pastagens de capim-elefante (Pennisetum purpureum Schum. cv. Cameroon): uma variável, determinada pela entrada dos animais na área a ser pastejada, quando o dossel atingisse $95 \%$ de interceptação da radiação fotossinteticamente ativa; e uma frequência fixa, de 26 dias. Utilizaram-se oito vacas com média de 124 dias em lactação, $516 \mathrm{~kg}$ de peso corporal e 17,5 kg de leite no início do experimento. O período experimental foi de 80 dias, divididos em quatro subperíodos de 20 dias. O delineamento experimental utilizado foi o crossover. As frequências de pastejo não influenciaram a produção e composição do leite, o nitrogênio ureico no plasma, o escore de condição corporal e a variação de peso corporal. Entretanto, a taxa de lotação e a produção de leite por unidade de área foram maiores nas pastagens com intervalo de pastejo determinado pela interceptação de $95 \%$ da radiação fotossinteticamente ativa. Assim, a frequência de pastejo definida em intervalos variáveis por meio da interceptação da radiação fotossinteticamente ativa resulta em maior produção de leite por unidade de área.

Palavras-chave: forragem, manejo do pastejo, pastagem, Pennisetum purpureum, produção de leite, vacas leiteiras

\section{Milk production and composition of dairy cows grazing elephant grass under two grazing intervals}

\begin{abstract}
The objective of this study was to evaluate two grazing intervals (IG) for elephant grass (Pennisetum purpureum Schum cv. Cameroon) pasture: one variable, determined by the entry of animals to the paddocks when $95 \%$ of active photosynthetic radiation was intercepted by the sward, and fixed 26-day grazing interval. Eight dairy cows were used, averaging 124 days lactation, $516 \mathrm{~kg}$ body weight and $17.5 \mathrm{~kg}$ daily milk production at the beginning of the trial. The experimental period was 80 days divided into four sub-periods of 20 days each. Data were analyzed in a cross-over design The grazing frequencies did not influence milk production and composition, plasma urea nitrogen, body condition score and variations in body weight. However, the stocking rate and milk production per hectare were higher for pasture with interval of grazing determined by $95 \%$ of active photosynthetic radiation. Thus grazing frequency defined in variable intervals by sward interception of active photosynthetic radiation result in higher milk production per area unit.
\end{abstract}

Key Words: forage, dairy cows, grassland, milk production, pasture management, Pennisetum purpureum

\section{Introdução}

Na maioria dos sistemas de produção de carne ou de leite no Brasil que adotam a lotação rotativa, são utilizados intervalos de pastejos fixos para estabelecer a frequência de desfolhação das pastagens (Voltolini, 2006).

Entretanto, o crescimento e o desenvolvimento da planta forrageira são determinados pela composição genética e pelas condições ambientais, como a fertilidade do solo e outras características do ambiente que podem potencializar ou retardar o crescimento da forrageira. Dessa forma, o estabelecimento do ciclo de pastejo em intervalos com número de dias fixos pode promover a desfolhação precoce ou tardia do dossel forrageiro, o que pode representar prejuízos à produção, à qualidade e à eficiência de colheita da forragem (Candido et al., 2006; Marcelino et al., 2006).

Esses prejuízos incluem menor produção de matéria seca (MS), em decorrência de colheitas precoces da forragem, prejudicando o crescimento da planta forrageira, 
ou do fato de o dossel forrageiro apresentar exacerbado processo de senescência em consequência de desfolhações tardias em relação ao que indica a fisiologia da planta forrageira de clima tropical (Carnevalli et al., 2006).

O uso de estratégias de manejo do pastejo de forrageiras tropicais baseadas em características ecofisiológicas tem apresentado alta similaridade com os resultados obtidos com plantas de clima temperado. São utilizadas características como o índice de área foliar (IAF), o número de folhas vivas por perfilho ou a interceptação da radiação fotossinteticamente ativa pelo dossel de plantas. Isso projeta boas perspectivas de manejo e utilização das plantas forrageiras tropicais (Carnevalli et al., 2006).

Assim, intervalos de pastejos variáveis ou mais curtos que os utilizados atualmente, principalmente na estação chuvosa, são estratégias eficientes para definir a frequência de pastejo. Essa proposta baseia-se nas influências que as plantas forrageiras sofrem dos fatores ambientais, que promovem alterações tanto na produção quanto na qualidade da forragem. Esses fatores determinarão a dinâmica de crescimento da planta e o melhor momento para o pastejo (Gomide et al., 2007).

O objetivo neste estudo foi avaliar duas estratégias de manejo do pastejo sobre o desempenho produtivo individual e por área, a composição nutricional do leite, os teores de nitrogênio ureico no leite e no plasma e a variação no peso corporal e no escore de condição corporal de vacas lactantes mantidas em pastagens de capim-elefante.

\section{Material e Métodos}

O trabalho foi conduzido no sistema de produção do Centro de Treinamento de Recursos Humanos do Departamento de Zootecnia da USP/ESALQ, em Piracicaba, SP.

As frequências de pastejo consistiram de dois intervalos de pastejo: um estabelecido pela entrada dos animais nos piquetes quando apresentavam $95 \%$ de interceptação da radiação fotossinteticamente ativa pelo dossel; e outro fixo, de 26 dias.

Foram utilizados 2,8 hectares de pastagem de capimelefante (Pennisetum purpureum Schum.), cv. Cameroon, divididos em 56 piquetes de $500 \mathrm{~m}^{2}$. Para cada frequência de pastejo, foram disponibilizados 28 piquetes. O delineamento experimental utilizado foi o cross-over, com oito vacas sorteadas ao acaso nas duas frequências de pastejo, com inversão a cada subperíodo.

Os resultados das análises químicas do solo na camada de 0 a $20 \mathrm{~cm}$ da área experimental foram os seguintes: 5,60 de $\mathrm{pH} ; 37 \mathrm{~g} / \mathrm{dm}^{3}$ de matéria orgânica; $30,30 \mathrm{mg} / \mathrm{dm}^{3}$ de fósforo; 7,07 $\mathrm{mmol}_{\mathrm{c}} / \mathrm{dm}^{3}$ de potássio; $47 \mathrm{mmol}_{\mathrm{c}} / \mathrm{dm}^{3} \mathrm{de}$ cálcio; $28 \mathrm{mmol}_{\mathrm{c}} / \mathrm{dm}^{3}$ de magnésio; $0 \mathrm{mmol}_{\mathrm{c}} / \mathrm{dm}^{3} \mathrm{de}$ alumínio; $20 \mathrm{mmol}_{\mathrm{c}} / \mathrm{dm}^{3}$ de alumínio e hidrogênio $(\mathrm{H}+\mathrm{Al})$; $82,30 \mathrm{mmol}_{\mathrm{c}} / \mathrm{dm}^{3}$ de soma de bases; $102,30 \mathrm{mmol}_{\mathrm{c}} / \mathrm{dm}^{3} \mathrm{de}$ capacidade de troca catiônica; $80,30 \%$ de saturação de bases; $0 \%$ de saturação por alumínio; $0,58 \mathrm{mg} / \mathrm{dm}^{3}$ de boro; $7,80 \mathrm{mg} / \mathrm{dm}^{3}$ de cobre $; 0 \mathrm{mg} / \mathrm{dm}^{3}$ de ferro; $60,60 \mathrm{mg} / \mathrm{dm}^{3} \mathrm{de}$ manganês e $6,40 \mathrm{mg} / \mathrm{dm}^{3}$ de zinco.

O período experimental teve início em fevereiro de 2004 e estendeu-se até abril do mesmo ano, com duração de 80 dias, divididos em quatro subperíodos de 20 dias. Em cada subperíodo, foram destinados 17 dias para adaptação dos animais e três dias para coleta de dados na pastagem e nos animais.

O período de ocupação dos piquetes, independentemente da frequência de pastejo, foi de dois dias, um dia para as vacas-teste e reguladoras, denominado pastejo de ponta, e um dia para os animais de repasse (vacas nãolactantes e em crescimento). O período de descanso das pastagens foi variável, no caso da frequência de pastejo variável, ou fixo, de 26 dias, no caso da frequência de pastejo fixa.

Em cada piquete, foram realizadas 20 leituras de interceptação da radiação fotossinteticamente ativa, no nível do solo. Na frequência de pastejo variável, no mesmo dia, mais de um piquete esteve apto ao pastejo. Nesse caso, os animais do pastejo de ponta foram alocados no piquete com o valor mais próximo a $95 \%$ de interceptação da radiação fotossinteticamente ativa e os demais piquetes dessa frequência de pastejo, em condições de pastejo, foram pastejados pelo lote de repasse. $\mathrm{Na}$ frequência de pastejo fixa, foi mensurada a interceptação da radiação fotossinteticamente ativa apenas no piquete a ser pastejado no dia.

As massas de forragem em pré e pós-pastejo foram estimadas por meio de coleta de amostras, utilizando-se moldura quadrada $\left(1 \mathrm{~m}^{2}\right)$. Coletaram-se duas amostras aleatórias em pré e pós-pastejo de cada um dos três piquetes pastejados de cada frequência de pastejo, durante os três dias do período de coleta em cada um dos quatro subperíodos experimentais. Dos 28 piquetes de cada frequência de pastejo, alguns foram amostrados mais de uma vez, enquanto outros não foram amostrados, em decorrência das datas de coleta e do ciclo de pastejo.

A amostragem da massa de forragem pré-pastejo foi obtida antes do pastejo do lote de vacas-teste e reguladoras, com o corte da forragem efetuado rente ao solo. A massa de forragem pós-pastejo foi obtida após o pastejo do lote de repasse, também pelo corte das plantas rente ao solo. 
Uma terceira medida de massa de forragem foi efetuada no ponto da altura do resíduo do ciclo de pastejo anterior e utilizada para ajustar a taxa de lotação de cada piquete. A taxa de lotação foi ajustada diariamente utilizando-se $4 \mathrm{~kg}$ de MS para cada $100 \mathrm{~kg}$ de peso corporal (PC) ao dia, considerando a quantidade de forragem colhida acima do resíduo pós-pastejo do ciclo anterior.

As massas de folhas, colmos e material morto foram determinadas após a separação e quantificação do peso de cada um desses componentes a partir de subamostras da massa de forragem, tanto no pré quanto no pós-pastejo. As amostras de planta inteira, folhas, colmos e material morto, assim como dos demais componentes, foram pesadas in natura e levadas a estufa de circulação forçada de ar e mantidas por 48 horas a $55{ }^{\circ} \mathrm{C}$ para a quantificação dos teores de matéria seca.

A altura do dossel foi medida desde o nível do solo até a curvatura da última folha completamente expandida, ou seja, a altura comumente chamada de visada, utilizando-se régua de madeira com 2,50 $\mathrm{m}$ de comprimento, graduada em centímetros. Foram tomadas 20 medidas por piquete durante o período de coleta para o pré e para o pós-pastejo.

A interceptação da radiação fotossinteticamente ativa e o índice de área foliar do dossel foram determinados utilizando-se o equipamento da marca $L I$-COR modelo LAI 2000 (LI-COR, Lincoln, Nebraska, EUA). Durante o período de adaptação dos animais, a interceptação da radiação fotossinteticamente ativa foi medida em aproximadamente $60 \%$ dos dias. Dessa maneira, nesse período, alguns dos piquetes da frequência de pastejo variável foram pastejados de acordo com os resultados da avaliação visual. Durante o período de coleta de leite, o monitoramento da interceptação da radiação fotossinteticamente ativa foi feito diariamente.

As áreas foram adubadas apenas com fonte nitrogenada, no caso, nitrato de amônio. A dose aplicada a partir da roçada na primavera e durante todo o período experimental foi de $2 \mathrm{~kg} / \mathrm{ha}$ de nitrogênio por dia de intervalo de pastejo.

Foram utilizadas oito vacas lactantes da raça Holandesa (Tabela 1) como animais-teste e número variável de vacas reguladoras, para ajuste da taxa de lotação. Vacas não- lactantes e animais em crescimento foram utilizados para o repasse pós-pastejo, quando necessário.

Os animais receberam suplementação com $6,3 \mathrm{~kg}$ de MS/dia de concentrado, parcelados em dois fornecimentos diários. Os ingredientes utilizados na formulação do concentrado foram milho moído fino, polpa cítrica peletizada, farelo de soja, ureia e suplemento mineral e vitamínico (Tabela 2).

A quantidade de concentrado fornecida foi baseada na produção inicial média das vacas em lactação. A relação utilizada inicialmente foi de $2,78 \mathrm{~kg}$ de leite para cada quilograma de MS de concentrado fornecido e a dose de concentrado foi mantida até o final do ensaio. O concentrado foi formulado segundo o NRC (2001).

As vacas foram ordenhadas duas vezes ao dia, às $7 \mathrm{e}$ às $16 \mathrm{~h}$, e o concentrado foi fornecido individualmente após a ordenha da manhã e antes da ordenha da tarde.

As pesagens e as amostragens do leite foram realizadas nos três últimos dias do período de coleta, durante as duas ordenhas diárias. A produção individual das vacas foi registrada diariamente para obtenção do valor médio ao final de cada período de coleta. Para determinação da composição do leite, foram tomadas amostras proporcionais à produção individual do animal por ordenha. As amostras foram preservadas em frascos plásticos contendo conservante e encaminhadas à Clínica do leite, do Departamento de Zootecnia da USP/ESALQ, para análises dos teores de proteína, gordura, lactose, sólidos totais e nitrogênio ureico no leite.

A produção de leite corrigida para 3,5\% de gordura foi calculada a partir da equação [4324*PL $(\mathrm{kg})+$ 16,216*gordura (kg)], proposta por Tyrrel \& Reid (1965).

As taxas de lotação (TL) foram calculadas separadamente para o lote de vacas em lactação (pastejo de ponta) e para o lote de repasse. A equação para obtenção das taxas de lotação foi a seguinte: TL $(\mathrm{UA} / \mathrm{ha})=\mathrm{UA} / \mathrm{S}$, em que UA = unidade animal ( $1 \mathrm{UA}=450 \mathrm{~kg}$ de $\mathrm{PC}) ; \mathrm{S}=$ tamanho da área (ha); ou TL (vacas/ha) $=$ vacas $/ \mathrm{S}$, em vacas $=$ número de vacas (pastejo de ponta). Nesse cálculo foi considerada apenas a área útil pastejada por cada grupo de animais, ou seja, 26 e 20 piquetes para as frequências de pastejo fixa e variável, respectivamente. Para obtenção da taxa de

Tabela 1 - Características das vacas-teste lactantes utilizadas no experimento

\begin{tabular}{|c|c|c|c|c|}
\hline Componente & Média & Desvio-padrão & Mínimo & Máximo \\
\hline Produção de leite, $\mathrm{kg} / \mathrm{dia}$ & 17,5 & 2,0 & 14,6 & 19,8 \\
\hline Número de partos & 3,60 & 1,60 & 2 & 6 \\
\hline Estádio de lactação, dias & 124 & 74 & 30 & 240 \\
\hline Peso corporal, kg & 516 & 37 & 489 & 578 \\
\hline Escore de condição corporal & 2,28 & 0,32 & 2,00 & 2,75 \\
\hline
\end{tabular}


Tabela 2 - Composição em ingredientes e nutricional do concentrado experimental

\begin{tabular}{lc}
\hline Ingrediente & \% de matéria seca \\
\hline Milho moído fino & 38,50 \\
Polpa cítrica peletizada & 38,50 \\
Ureia & 1,27 \\
Farelo de soja & 17,0 \\
Suplemento mineral e vitamínico & 4,80 \\
Composição nutricional & \\
Energia metabolizável, Mcal/kg & 2,66 \\
Proteína bruta, \% da MS & 18,0 \\
Fibra em detergente neutro, \% da MS & 14,7 \\
Fibra em detergente ácido, \% da MS & 9,3
\end{tabular}

lotação do pastejo de repasse, utilizou-se o mesmo critério. A partir dos valores das taxas de lotação (vacas/ha) calculadas e da produção de leite observada (kg/vaca.dia), foram estimadas as produções de leite por unidade de área ( $\mathrm{kg}$ de leite/ha.dia) para cada frequência de pastejo.

A coleta de sangue foi realizada no último dia de cada período de coleta, sempre 4 horas após o fornecimento matinal do concentrado, por meio de punção na veia coccígea. As amostras de sangue foram armazenadas em tubos de ensaio a vácuo, contendo $5 \mathrm{mg}$ de fluoreto de sódio como anticoagulante. O plasma obtido após centrifugação foi analisado em laboratório comercial para determinação da concentração de nitrogênio ureico no plasma.

O escore de condição corporal (ECC) foi avaliado no primeiro e último dia de cada subperíodo, sempre pelo mesmo indivíduo. A escala utilizada variou de 1 a 5 pontos, de modo que 1 representava vacas muito magras e 5, vacas excessivamente gordas, classificadas a intervalos de 0,25 ponto, de acordo com Wildman et al. (1982).

Da mesma forma, a pesagem dos animais foi feita no primeiro e último dia de cada subperíodo, após a ordenha da tarde. Entre as duas pesagens, foi considerado o menor peso para a análise dos dados.

As análises estatísticas foram realizadas por meio do PROC GLM (General linear models) do Statistical Analysis System (SAS, 1999) utilizando-se o modelo estatístico:

$\mathrm{Y}_{\mathrm{ijkl}}=\mu+\mathrm{A}_{\mathrm{i}}+\mathrm{SP}_{\mathrm{j}}+\mathrm{T}_{\mathrm{k}}+\mathrm{S}_{1}+\mathrm{e}_{\mathrm{ijk} \mathrm{k}}$, em que: $\mathrm{Y}_{\mathrm{ijkl}}=$ variáveis observadas; $\mu$ média geral; $\mathrm{A}_{\mathrm{i}}=$ efeito do animal $\mathrm{i}$, $\left({ }_{i}=1,2 \ldots 8\right) ; \mathrm{SP}_{j}=$ efeito do subperíodo $_{j}\left({ }_{\mathrm{j}}=1,2,3\right.$ e 4); $\mathrm{T}_{\mathrm{k}}=$ efeito do tratamento ${ }_{\mathrm{k}}\left(\mathrm{k}=1\right.$ e 2); $\mathrm{S}_{1}=$ efeito da sequência ${ }_{1}(1=1$ e 2$) ; e_{i j k l}=$ erros associados às observações $\mathrm{Y}_{\mathrm{ijk} 1}$. Considerou-se significativo o nível de 5\% de probabilidade $(\mathrm{P}<0,05)$. Todas as médias foram obtidas utilizando-se o método dos quadrados mínimos.

\section{Resultados e Discussão}

O intervalo de pastejo, a altura do dossel no pré e póspastejo, a interceptação da radiação fotossinteticamente ativa e o índice de área foliar foram maiores $(\mathrm{P}<0,05)$ na frequência de pastejo fixa (Tabela 3 ). Não houve efeito $(\mathrm{P}>0,05)$ da frequência de pastejo sobre as massas de forragem, de folhas e de colmos pré e pós-pastejo. A massa de material morto foi menor $(\mathrm{P}<0,05)$ na frequência de pastejo variável, tanto no pré quanto no pós-pastejo.

A adoção do intervalo de pastejo variável, em comparação ao intervalo fixo, possibilitou obter, por meio do aumento na frequência de desfolhação, maior número de ciclos de pastejo, o que levou a maior produção de forragem no período de utilização das pastagens. Além disso, o intervalo de pastejo determinado pela interceptação de $95 \%$ da radiação fotossinteticamente ativa também resultou em menores alturas dos dosséis pré e pós-pastejo, o que indica melhor controle no desenvolvimento dos

Tabela 3 - Caracterização das pastagens de capim-elefante submetidas a duas frequências de pastejo

\begin{tabular}{|c|c|c|c|c|}
\hline \multirow[t]{2}{*}{ Componente } & \multicolumn{2}{|c|}{ Frequência de pastejo } & \multirow[t]{2}{*}{$\mathrm{EPM}^{2}$} & \multirow[t]{2}{*}{ Valor de $\mathrm{P}^{1}$} \\
\hline & RFA95 & IPF26 & & \\
\hline Interceptação da radiação fotossinteticamente ativa, \% & 95,47 & 97,91 & 0,17 & 0,0001 \\
\hline Intervalo de pastejo, dias & 19,4 & 26,0 & 0,25 & 0,0001 \\
\hline Altura do dossel pré-pastejo, metros & 1,03 & 1,21 & 0,02 & 0,0001 \\
\hline Altura do dossel pós-pastejo, metros & 0,62 & 0,71 & 0,02 & 0,01 \\
\hline Índice de área foliar, pontos & 3,80 & 4,73 & 0,08 & 0,0001 \\
\hline Massa de forragem pré-pastejo, $\mathrm{kg} / \mathrm{ha}$ de MS & 6.270 & 6.310 & 490 & 0,96 \\
\hline Massa de forragem pós-pastejo, $\mathrm{kg} / \mathrm{ha}$ de MS & 3.580 & 3.850 & 350 & 0,38 \\
\hline Massa de folhas pré pastejo, $\mathrm{kg} / \mathrm{ha}$ de MS & 3.440 & 3.250 & 150 & 0,38 \\
\hline Massa de colmos pré pastejo, $\mathrm{kg} / \mathrm{ha}$ de MS & 2.720 & 3.094 & 80 & 0,07 \\
\hline Massa de material morto pré pastejo, $\mathrm{kg} / \mathrm{ha}$ de $\mathrm{MS}$ & 330 & 425 & 20 & 0,008 \\
\hline Massa de folhas pós pastejo, $\mathrm{kg} / \mathrm{ha}$ de MS & 820 & 732 & 40 & 0,10 \\
\hline Massa de colmos pós pastejo, $\mathrm{kg} / \mathrm{ha}$ de $\mathrm{MS}$ & 2.440 & 2.720 & 120 & 0,10 \\
\hline Massa de material morto pós pastejo, $\mathrm{kg} / \mathrm{ha}$ de $\mathrm{MS}$ & 300 & 360 & 15 & 0,004 \\
\hline
\end{tabular}

RFA95 = intervalo de pastejo determinado pela interceptação de $95 \%$ da radiação fotossinteticamente ativa; IPF26 = intervalo de pastejo fixo de 26 dias

${ }^{1}$ Probabilidade; ${ }^{2}$ Erro-padrão da média. 
colmos e na manutenção da altura do resíduo pós-pastejo, grandes desafios do manejo do pastejo do capim-elefante.

Os valores de massa de forragem em pré-pastejo deste estudo foram menores que os obtidos por Balsalobre (1996), Martinez (2004) e Voltolini et al. (2008) na mesma área experimental. Esses autores relataram valores de $8.000 \mathrm{a}$ $16.000 \mathrm{~kg} / \mathrm{ha}$ de MS por ciclo de pastejo com períodos de descanso de 38 a 40 dias. As massas de forragem dos resíduos pós-pastejo nesses trabalhos foram excessivamente altas e variaram de 6.000 a $10.700 \mathrm{~kg} / \mathrm{ha}$ de MS, compostas principalmente por colmos e material morto, enquanto nesta pesquisa variaram de 3.580 a $3.850 \mathrm{~kg} / \mathrm{ha}$ de MS.

Apesar de as massas de forragem em pré-pastejo encontradas neste estudos terem sido inferiores às descritas por Balsalobre (1996), Martinez(2004)e Voltolini et al. (2008), a massa de folhas foi semelhante, o que indica alta participação de colmos e material morto com o avanço do período de descanso.

O valor de $97,91 \%$ de interceptação da radiação fotossinteticamente ativa, associado às maiores massas de material morto pré e pós-pastejo na frequência de pastejo fixa, sugere que esse período de descanso é excessivo para o capim-elefante nas condições avaliadas. Por outro lado, intervalos de pastejos inferiores a 20 dias poderão comprometer a rebrotação da planta forrageira, principalmente em condições de veranicos e nas transições entre as estações das águas e seca. Desse modo, são boas as perspectivas para o uso de pastagens de capim-elefante com períodos de descanso de 20 a 26 dias.

A altura do dossel em pré-pastejo também é uma boa característica para estabelecer o melhor momento da colheita da planta forrageira. Em avaliação com capim-elefante durante 80 dias, Voltolini (2006) observou forte correlação entre a altura do dossel em pré-pastejo com os valores de interceptação da radiação fotossinteticamente ativa. Segundo esse autor, com $95 \%$ de radiação fotossinteticamente ativa, o dossel de capim-elefante apresentava de 1,00 a 1,05 m de altura. O resultado do estudo confirmou que o intervalo de altura do dossel proposto por Voltolini (2006) em pré-pastejo do capim-elefante pode ser boa estratégia para determinar o momento do pastejo.

De modo geral, os resultados observados com o capimelefante manejado com intervalos de pastejo definidos pela interceptação de $95 \%$ da radiação fotossinteticamente ativa permitem respostas produtivas, morfológicas e estruturais semelhantes às observadas com outras plantas forrageiras de clima tropical usando o mesmo critério de manejo, por exemplo, os capins mombaça (Carnevalli et al., 2006), tanzânia (Mello \& Pedreira, 2004; Barbosa et al., 2007) e xaraés (Pedreira et al., 2007).

A produção de leite, a produção de leite corrigida para 3,5\% de gordura, a composição nutricional do leite (gordura, proteína, lactose e sólidos totais), o nitrogênio ureico no leite e o nitrogênio ureico no plasma não foram influenciados $(\mathrm{P}>0,05)$ pelas frequências de pastejo (Tabela 4 ).

Os valores médios encontrados para a produção de leite foram inferiores aos relatados por Martinez (2004) e Voltolini et al. (2008), que obtiveram produções de 17,9 a $20,0 \mathrm{~kg} / \mathrm{vaca}$.dia utilizando pastagens de capim-elefante em lotação rotativa e suplementação com 4,5 a 6,3 kg/vaca de MS de concentrado por dia. Entretanto, tanto Martinez (2004) quanto Voltolini et al. (2008) utilizaram vacas lactantes em estádios de lactação menos avançados que as deste trabalho.

Apesar de as frequências de pastejo proporcionarem algumas alterações na planta forrageira, essas mudanças não foram suficientes para aumentar a produção individual de leite. Aparentemente, a eficiência de utilização da planta forrageira e o consumo de MS não foram afetados pelos

Tabela 4 - Produção e composição do leite, nitrogênio ureico no leite e no plasma de vacas lactantes em pastagens de capim-elefante submetidas a duas frequências de pastejo

\begin{tabular}{|c|c|c|c|c|}
\hline \multirow[t]{2}{*}{ Componente } & \multicolumn{2}{|c|}{ Frequência de pastejo } & \multirow[t]{2}{*}{$\mathrm{EPM}^{2}$} & \multirow[t]{2}{*}{ Valor de $\mathrm{P}^{1}$} \\
\hline & RFA95 & IPF26 & & \\
\hline Leite, $\mathrm{kg} / \mathrm{dia}$ & 16,72 & 14,09 & 0,90 & 0,12 \\
\hline Leite corrigido para $3,5 \%$ de gordura, $\mathrm{kg} / \mathrm{dia}$ & 17,65 & 14,88 & 0,88 & 0,10 \\
\hline Gordura, \% & 3,98 & 3,75 & 0,10 & 0,21 \\
\hline Gordura, kg/dia & 0,64 & 0,54 & 0,03 & 0,08 \\
\hline Proteína, \% & 3,23 & 3,08 & 0,15 & 0,60 \\
\hline Proteína, kg/dia & 0,52 & 0,44 & 0,04 & 0,26 \\
\hline Lactose, $\%$ & 4,40 & 4,06 & 0,19 & 0,29 \\
\hline Lactose, $\mathrm{kg} / \mathrm{dia}$ & 0,72 & 0,58 & 0,04 & 0,11 \\
\hline Sólidos Totais, \% & 12,56 & 11,75 & 0,46 & 0,32 \\
\hline Sólidos Totais, kg/dia & 2,04 & 1,70 & 0,11 & 0,12 \\
\hline Nitrogênio ureico no leite, $\mathrm{mg} / \mathrm{dL}$ & 13,78 & 13,89 & 0,36 & 0,89 \\
\hline Nitrogênio ureico no plasma, mg/dL & 19,20 & 19,51 & 1,23 & 0,70 \\
\hline
\end{tabular}

RFA95 = intervalo de pastejo determinado pela interceptação de $95 \%$ da radiação fotossinteticamente ativa; IPF26 = intervalo de pastejo fixo de 26 dias

1 = Probabilidade; ${ }^{2}=$ erro-padrão da média. 
períodos de descanso, contudo, apesar de não-significativa, a diferença na produção de leite entre as vacas das duas frequências de pastejo foi de 2,63 kg/dia. De forma semelhante, Wendling et al. (2004) não observaram efeitos da redução no período de descanso do capimelefante de 30 para 24 dias sobre a produção de leite das vacas. Deresz (2001), no entanto, observou maior produção de leite de vacas mantidas em pastagens de capim-elefante com 30 ou 36 dias de descanso, em comparação ao intervalo de pastejo de 45 dias, e recomendaram o período de descanso de 30 dias.

A composição nutricional do leite e as concentrações de nitrogênio ureico no leite e no plasma foram semelhantes aos valores reportados por Martinez (2004) e Voltolini et al. (2008) para vacas em lactação mantidas em pastagens de capim-elefante em lotação rotativa recebendo suplementação com concentrado. Os valores de nitrogênio ureico no leite e nitrogênio ureico no plasma observados indicam excesso de proteína na ração total das vacas e sugerem que o teor de $18 \%$ de proteína bruta (PB) na MS do concentrado fornecido foi excessivo.

Voltolini etal. (2008) demonstraram que, em pastagens de capim-elefante com $12 \%$ de PB, vacas com produções de leite de $18,5 \mathrm{~kg} /$ dia não responderam ao aumento de $\mathrm{PB}$ no concentrado para valores acima de $18 \%$ na MS. ONRC (2001) recomenda para vacas com produção de $16 \mathrm{~kg}$ de leite/dia, mantidas em pastagens com 14\% de PB suplementação com concentrado com teor de PB inferior a $15 \%$.

A taxa de lotação do pastejo de ponta foi $30 \%$ maior $(\mathrm{P}<0,05)$ e a produção de leite por área $34 \%$ maior na frequência de pastejo variável (Tabela 5). Essa vantagem expressiva da frequência de pastejo variável foi resultado direto da taxa de lotação. A maior taxa de lotação obtida com essa frequência de pastejo se deve ao menor número de piquetes utilizados ao longo de todo o ciclo de pastejo, proporcionado pela redução no intervalo de pastejo. Enquanto na frequência de pastejo fixa foram utilizados 26 piquetes, na frequência de pastejo variável, foram necessários apenas 20 piquetes. A elevada taxa de crescimento do capim-elefante no verão é uma das justificativas para os resultados observados.

De acordo com Marcelino et al. (2006), que avaliaram diferentes frequências e intensidades de pastejo do capimbraquiária (Brachiaria brizantha cv. Marandu), colheitas mais frequentes ocasionam aumento da renovação de tecidos. Observação semelhante foi constatada por Candido et al. (2005), que relataram redução na taxa de acúmulo de forragem com o avanço do período de descanso de pastagens de capim-mombaça (Panicum maximum cv. Mombaça). Esse aumento na produtividade, se confirmado em trabalhos posteriores, terá impacto significativo na rentabilidade de sistemas comerciais de produção de leite em pastagens de capim-elefante.

$\mathrm{O}$ escore de condição corporal e a variação no peso corporal não diferiram $(\mathrm{P}>0,05)$ entre as frequências de pastejo. A ausência de efeitos das frequências de pastejo sobre o ganho de peso ou escore de condição corporal estão de acordo com a ausência de efeito significativo na produção e composição nutricional do leite.

Os valores obtidos neste estudo para as variações no escore de condição corporal e para a variação do peso corporal foram semelhantes aos reportados por Martinez (2004) e Voltolini et al. (2008), que encontraram valores de 4,0 a $6,0 \mathrm{~kg}$ e 0,01 a 0,10 ponto, respectivamente, para a variação do peso corporal e a variação no escore de condição corporal em vacas lactantes mantidas em pastagens de capim-elefante recebendo suplementação com concentrado em subperíodos de 20 dias.

Tabela 5 - Taxa de lotação do pastejo de ponta (vacas em lactação) e do pastejo repasse (vacas não-lactantes e animais em crescimento), produção de leite por área em pastagens de capim-elefante submetidas a duas frequências de pastejo

\begin{tabular}{lccc}
\hline Componente & \multicolumn{2}{c}{ Frequência de pastejo } & \multirow{2}{*}{ EPM $^{2}$} \\
\cline { 2 - 3 } & RFA95 & IPF26 & \\
\hline Taxa de lotação, vacas/ha & 7,18 & 5,05 & 0,42 \\
Taxa de lotação, UA/ha & 8,27 & 5,85 & 0,002 \\
Produção de leite, kg/ha/dia & 114 & 75 & 0,02 \\
Taxa de lotação repasse, UA/ha & 2,83 & 3,00 & 6,40 \\
\hline
\end{tabular}

RFA95 = intervalo de pastejo determinado pela interceptação de $95 \%$ da radiação fotossinteticamente ativa; IPF $26=$ intervalo de pastejo fixo de 26 dias

${ }^{1}$ Probabilidade; ${ }^{2}$ Erro-padrão da média.

\section{Conclusões}

O intervalo de pastejo definido pela interceptação de $95 \%$ da radiação fotossinteticamente ativa resulta em maiores taxas de lotação e produção de leite por unidade de área em relação ao intervalo de pastejo fixo de 26 dias. Os intervalos de pastejo avaliados não afetam a produção individual, a composição nutricional do leite, os teores de nitrogênio ureico no leite e no plasma, o peso corporal e o escore de condição corporal das vacas lactantes. 


\section{Referências}

BALSALOBRE, M.A.A. Desempenho de vacas em lactação sob pastejo rotacionado de capim-elefante (Pennisetum purpureum Schum.). 1996. 139f. Dissertação (Mestrado em Ciência Animal e Pastagem) - Escola Superior de Agricultura "Luiz de Queiroz"/Universidade de São Paulo, Piracicaba.

BARBOSA, R.A.; NASCIMENTO JR., D.; EUCLIDES, V.P.B. et al. Capim Tanzânia submetido a combinações entre intensidade e frequência de pastejo. Pesquisa Agropecuária Brasileira, v.42, p.329-340, 2007.

CANDIDO, M.J.D.; ALEXANDRINO, E.; GOMIDE, J.A. Duração do período de descanso e crescimento do dossel de Panicum maximum cv. Mombaça sob lotação intermitente. Revista Brasileira de Zootecnia, v.34, n.2, p.398-405, 2005.

CANDIDO, M.J.D.; SILVA, R.G.; NEIVA, J.N.M. et al. Fluxo de biomassa em capim Tanzânia pastejado por ovinos sob três períodos de descanso. Revista Brasileira de Zootecnia, v.35, n.6, p.2234-2242, 2006.

CARNEVAlLI, R.A.; SILVA, S.C.; BUENO, A.A.O. et al. Herbage production and grazing losses in Panicum maximum cv. Mombaça under four grazing managements. Tropical grasslands, v.40, p.165-176, 2006.

DERESZ, F. Influência do período de descanso da pastagem de capim Elefante na produção de vacas mestiças Holandês-Zebu. Revista Brasileira de Zootecnia, v.30, n.2, p.461-469, 2001.

GOMIDE, C.A.M.; GOMIDE, J.A.; ALEXANDRINO, E. Características estruturais e produção de forragem em pastos de capim mombaça submetidos a períodos de descanso. Pesquisa Agropecuária Brasileira, v.42, n.10, p.1487-1494, 2007.

MARCELINO, K.R.A.; NASCIMENTO JR., D.; SILVA, S.C. et al. Características morfogênicas e estruturais e produção de forragem do capim marandu submetido a intensidades e frequências de desfolhações. Revista Brasileira de Zootecnia, v.35, n.6, p.2243-2252, 2006.

MARTINEZ, J.C. Substituição do milho moído fino por polpa cítrica peletizada no concentrado de vacas leiteiras mantidas em pastagens de capim-elefante durante o outono-inverno. 2004. 110f. Dissertação (Mestrado em Ciência Animal e Pastagem) - Escola Superior de Agricultura "Luiz de Queiroz", Piracicaba.

MELLO, A.C.L.; PEDREIRA, C.G.S. Respostas morfofisiológicas do capim Tanzânia (Panicum maximum cv. Tanzânia-1) irrigado à intensidade de desfolha sob lotação rotacionada. Revista Brasileira de Zootecnia, v.33, p.282-289, 2004.

NATIONAL RESEARCH COUNCIL - NRC. Nutrient requeriments of dairy cattle. 7.ed. Washington, D,C.: National Academic Press, 2001. 408p.

PEDREIRA, B.C.; PEDREIRA, C.G.S.; SILVA, S.C. Estrutura do dossel e acúmulo de forragem de Brachiaria brizantha cultivar Xaraés em resposta a estratégias de pastejo. Pesquisa Agropecuária Brasileira, v.42, n.2, p.281-287, 2007.

STATISTICAL ANALYSIS SYSTEM - SAS. SAS user's guide: statistics; version 8. Cary: SAS Institute, 1999. 965p.

TYRRELL, H.F.; REID, J.T. Prediction of energy value of cow's milk. Journal of Dairy Science, v.48, p.1215-1223, 1965.

VOLTOLINi, T.V. Adequação protéica em rações com pastagens ou com cana-de-açúcar e efeito de diferentes intervalos entre desfolhas sobre o desempenho lactacional de vacas leiteiras. 2006. 167f. Tese (Doutorado em Ciência Animal e Pastagem) - Escola Superior de Agricultura "Luiz de Queiroz", Piracicaba.

VOLTOLINI, T.V.; SANTOS, F.A.P.; MARTINEZ, J.C. et al. Metabolizable protein supply according to the NRC (2001) for dairy cows grazing elephant grass. Scientia Agricola, v.65, n.2, p.130-138, 2008.

WENDLING, I.J.; ALENCAR, C.A.B.; TEIXEIRA, S.R. et al. Produção de leite de vacas mestiças Holandês x Zebu em pastagem de capim elefante (cv. Pioneiro) submetido a dois períodos de descanso. In: REUNIÃO ANUAL DA SOCIEDADE BRASILEIRA DE ZOOTECNIA, 41., 2004, Campo Grande. Anais... Campo Grande: Sociedade Brasileira de Zootecnia, 2004. (CD-ROM).

WILDMAN, E.E.; JONES, G.M.; WAGNER, P.E. et al. A dairy condition scoring system and its relationship to selected production characteristics. Journal of Dairy Science, v.65, p.495-501, 1982 . 